\title{
Postpartum Implanon/Nexplanon continuation rates and associated factors among women who ever used Implanon/Nexplanon in a tertiary hospital in Accra, Ghana
}

\author{
Kareem Mumuni' ${ }^{1 *}$, Kwaku Asah-Opoku¹, Vincent Ganu², Ali Samba1
}

${ }^{1}$ Department of Obstetrics and Gynecology, University of Ghana School of Medicine and Dentistry (UGSMD), Korle$\mathrm{Bu}$, Accra, Ghana

${ }^{2}$ Korle-Bu Teaching Hospital, Department of Medicine-Fevers Unit, Korle-Bu, Ghana

Received: 24 April 2019

Revised: 30 May 2019

Accepted: 05 June 2019

\section{*Correspondence:}

Dr. Kareem Mumuni,

E-mail: mumunikareem@yahoo.co.uk

Copyright: (c) the author(s), publisher and licensee Medip Academy. This is an open-access article distributed under the terms of the Creative Commons Attribution Non-Commercial License, which permits unrestricted non-commercial use, distribution, and reproduction in any medium, provided the original work is properly cited.

\section{ABSTRACT}

Background: Postpartum Implanon use serves as an important conduit to bridge the wide gap of unmet need for contraception. The study sought to determine the continuation rates of postpartum Implanon/Nexplanon use and factors associated with it.

Methods: A retrospective review of electronic data of 391 women who had received postpartum Implanon/Nexplanon insertions from January 2012 to December 2015 was conducted at a family planning hospital in Accra, Ghana. Continuation rates and factors associated with discontinuation at 6 months, one year and two years post-partum were determined. Data were analysed using IBM Statistical Package for Social Science (SPSS) version 20.

Results: A total of 391 postpartum Implanon/Nexplanon insertions were done during study period. Their mean age was $28.51 \pm 5.29$ years and median parity was 2.0. Continuation rates of postpartum Implanon/Nexplanon at 6 months, 1 year and 2 years post uptake were $94.9 \%, 92.8 \%$ and $86.4 \%$ respectively. Women with tertiary level education were $64 \%$ less likely to continue Implanon/Nexplanon use at one-year post uptake $(\mathrm{OR}=0.36, \mathrm{CI}=0.16-0.85)$. Women with education up to Senior High School were $62 \%$ less likely to continue postpartum Implanon/Nexplanon use at 2 years after uptake $(\mathrm{OR}=0.38, \mathrm{CI}=0.18-0.81)$. Women between ages 20 and 29 years were $53 \%$ less likely to continue postpartum Implanon/Nexplanon use at 2 years $(\mathrm{OR}=0.47, \mathrm{CI}=0.26-0.86)$. Reasons for discontinuation of postpartum Implanon/Nexplanon use were wishes to get pregnant and side effects of the method.

Conclusions: Post -partum Implanon/Nexplanon continuation rates are high and remain as a viable choice for reduction of unplanned pregnancies post- delivery.

Keywords: Continuation rates, Discontinuation, Implanon/Nexplanon, Post-partum

\section{INTRODUCTION}

The unmet need for contraception in Ghana is high. The contraceptive prevalence rate is $27 \% .^{1}$ The use of contraception remains a viable avenue to reduce maternal mortality rates. ${ }^{2,3}$ Post-partum Implanon as long acting reversible contraceptive has been found to be very effective. $^{4,5}$ Postpartum usage of Implanon/Nexplanon is significant because the post-partum period serves as a window of opportunity where women who have delivered 
make contact with health facilities and can access health commodities like contraception. Though uptake of such contraception is important, it is more imperative to document the continuation rates and the factors associated with continuation or discontinuation of this contraceptive method. This is because most women discontinue the use of particular contraceptives when they are not on any back up method. ${ }^{6,7}$ Discontinuation of contraceptive use leads to consequences such as an unwanted or mistimed pregnancy. ${ }^{8}$ Nearly half of unwanted pregnancies result in unsafe abortion. ${ }^{9}$ There is however scarcity of data on the continuation rates of postpartum Implanon/Nexplanon in Ghana. Data on this will help in health systems strengthening and also the public health education drive to enhance continuation of Implanon/Nexplanon use. This study sought to assess the continuation rates of post-partum Implanon, the factors associated with continuation of post-partum Implanon/Nexplanon and to evaluate the reasons for discontinuation of post-partum Implanon/Nexplanon.

\section{METHODS}

A retrospective review of electronic data of 391 women who had received Implanon/Nexplanon immediately post-delivery up to one-year post-partum at the Reproductive Health and Family Planning Unit of the
Korle-Bu Teaching Hospital between January 2012 and December 2015 was conducted. The final extracted data was entered into Microsoft Office Excel 2010 then exported into the IBM Statistical Package for Social Science (SPSS) version 20 for data analysis. The data analysis was presented as frequencies, means and median and as tables and charts where necessary.

The categorical outcome variables and predictors of continuation of postpartum Implanon/Nexplanon use at 6 months, 1 year and 2 years were analysed using $\chi^{2}$ (chi square) test. $\mathrm{T}$ test was used to analyse the association between continuous outcome and selected independent variables. Odds ratios and their $95 \%$ confidence intervals (CI) were used to test the strength of association. In all the statistical procedure a P-value of less than 0.05 was considered statistically significant.

\section{RESULTS}

The total number of women who had taken up postpartum Implanon/Nexplanon during the study period were 391. The mean age was $28.51 \pm 5.29$ years and the median parity was 2.0 , with a range between $1-9$. The continuation rates of Implanon/Nexplanon among women within 6 months, one year and 2 years post-partum were $94.9 \%, 92.8 \%$ and $86.4 \%$ respectively (Figure 1).

Table 1: Effect of timing of uptake of postpartum Implanon/Nexplanon on continuation rates among women at the Korle-Bu Teaching Hospital 2012 -2015, Accra, Ghana.

\begin{tabular}{|c|c|c|c|c|}
\hline \multirow[b]{2}{*}{ Variable } & \multicolumn{4}{|l|}{ Six months } \\
\hline & $\begin{array}{l}\text { Yes } \\
N=371\end{array}$ & $\begin{array}{l}\text { No } \\
N=20\end{array}$ & OR (95\% C.I) & $P$ value \\
\hline \multicolumn{5}{|c|}{ Breakdown of post-partum uptake } \\
\hline 0 - 2 days (immediate) & $9(2.4)$ & $0(0.0)$ & - & 1.000 \\
\hline $3-42$ days (delayed) & $104(28.0)$ & $4(20.0)$ & $1.56(0.51-4.77)$ & 0.609 \\
\hline \multirow{3}{*}{ 43-365 days (interval) } & $258(69.5)$ & $16(80.0)$ & $0.57(0.19-1.75)$ & 0.453 \\
\hline & \multicolumn{4}{|c|}{ Within one year } \\
\hline & $\begin{array}{l}\text { Yes } \\
N=363\end{array}$ & $\begin{array}{l}\text { No } \\
\mathrm{N}=\mathbf{2 8}\end{array}$ & & \\
\hline \multicolumn{5}{|c|}{ Breakdown of post-partum uptake } \\
\hline 0-2days (immediate) & $9(2.5)$ & $0(0.0)$ & - & 1.000 \\
\hline 3-42days (delayed) & $102(28.1)$ & $6(21.4)$ & $1.43(0.56-3.64)$ & 0.518 \\
\hline \multirow[t]{3}{*}{ 43-365days (interval) } & $252(69.4)$ & $22(78.6)$ & $0.62(0.24-1.57)$ & 0.394 \\
\hline & \multicolumn{4}{|c|}{ Within two year } \\
\hline & $\begin{array}{l}\text { Yes } \\
\mathbf{N}=338\end{array}$ & $\begin{array}{l}\text { No } \\
N=53\end{array}$ & & \\
\hline \multicolumn{5}{|c|}{ Breakdown of post-partum uptake } \\
\hline 0-2days (immediate) & $8(2.4)$ & $1(1.9)$ & $1.26(0.15-10.29)$ & 1.000 \\
\hline 3-42days (delayed) & $97(28.7)$ & $11(20.8)$ & $1.54(0.76-3.11)$ & 0.252 \\
\hline 43-365days (interval) & $233(68.9)$ & $41(77.4)$ & $0.65(0.33-1.29)$ & 0.260 \\
\hline
\end{tabular}


Timing of uptake (immediate, interval or delayed postpartum) of Implanon/Nexplanon was not significantly associated with continuation rates (Table 1).

There was no significant association between any of the sociodemographic determinants considered and

continuation of postpartum Implanon/Nexplanon use at 6 months. (Table 2). Women with tertiary level education were $64 \%$ less likely to continue postpartum
Implanon/Nexplanon use at one-year post uptake $(\mathrm{OR}=0.36, \mathrm{CI}=0.16-0.85)$ (Table 3$)$.

Women with education up to Senior High School level were $62 \%$ less likely to continue postpartum Implanon/Nexplanon use at 2 years post uptake $(\mathrm{OR}=0.38, \mathrm{CI}=0.18-0.81)$ (Table 4). Women between ages 20 and 29 years were $53 \%$ less likely to continue postpartum Implanon/Nexplanon use at 2 years $(\mathrm{OR}=0.47, \mathrm{CI}=0.26-0.86)$ (Table 4).

Table 2: Sociodemographic determinants of continuation of Implanon/Nexplanon use at 6 months postpartum among women at the Korle-Bu Teaching Hospital 2012 -2015, Accra, Ghana.

\begin{tabular}{|c|c|c|c|c|}
\hline \multirow[b]{2}{*}{ Variable } & \multicolumn{4}{|c|}{ Postpartum Uptake } \\
\hline & $\begin{array}{l}\text { Yes } \\
\mathbf{N}=371\end{array}$ & $\begin{array}{l}\text { No } \\
\mathrm{N}=20\end{array}$ & OR (95\% C.I) & P-value \\
\hline \multicolumn{5}{|l|}{ Age group } \\
\hline$<20$ & $23(6.2)$ & $0(0.0)$ & - & 0.620 \\
\hline $20-29$ & $177(47.7)$ & $12(60.0)$ & $0.61(0.24-1.52)$ & 0.360 \\
\hline $30-39$ & $165(44.5)$ & $8(40.0)$ & $1.20(0.48-3.01)$ & 0.819 \\
\hline 40 and above & $6(1.6)$ & $0(0.0)$ & - & 1.000 \\
\hline \multicolumn{5}{|l|}{ Parity } \\
\hline P1 & $126(34.0)$ & $10(50.0)$ & $0.54(0.23-1.25)$ & 0.162 \\
\hline P2-P4 & 225 (60.6) & $10(50.0)$ & $1.41(0.61-3.29)$ & 0.522 \\
\hline P5 and above & $20(5.4)$ & $0(0.0)$ & - & 0.614 \\
\hline Abortions & $N=85$ & $\mathrm{~N}=9$ & & \\
\hline 1 & $45(52.9)$ & $7(77.8)$ & $0.32(0.06-1.64)$ & 0.181 \\
\hline 2 & $29(34.1)$ & $1(11.1)$ & $4.14(0.49-34.75)$ & 0.263 \\
\hline $3+$ & $11(12.9)$ & $1(11.1)$ & $1.19(0.13-10.45)$ & 1.000 \\
\hline Occupation & $\mathrm{N}=332$ & $\mathrm{~N}=19$ & & \\
\hline Professional & $111(33.4)$ & $8(42.1)$ & $0.69(0.27-1.77)$ & 0.461 \\
\hline Skilled & $60(18.1)$ & $4(21.1)$ & $0.83(0.27-2.58)$ & 0.760 \\
\hline Semi-skilled & $11(3.3)$ & $1(5.3)$ & $0.62(0.08-5.04)$ & 0.493 \\
\hline Trader & $100(30.1)$ & $4(21.1)$ & $1.62(0.52-4.99)$ & 0.606 \\
\hline Housewife & $8(2.4)$ & $0(0.0)$ & - & 1.000 \\
\hline Student & $22(6.6)$ & $1(5.3)$ & $1.28(0.16-10.02)$ & 1.000 \\
\hline Unemployed & $20(6.0)$ & $1(5.3)$ & $1.15(0.15-9.09)$ & 1.000 \\
\hline Educational level & $N=330$ & $N=19$ & & \\
\hline No formal education & $26(7.9)$ & $1(5.3)$ & $1.54(0.20-12.00)$ & 1.000 \\
\hline \multirow[b]{2}{*}{ Variable } & \multicolumn{2}{|c|}{ Postpartum uptake } & \multirow[b]{2}{*}{ OR (95\% C.I) } & \multirow[b]{2}{*}{ P-value } \\
\hline & $\begin{array}{l}\text { Yes } \\
\mathrm{N}=371\end{array}$ & $\begin{array}{l}\text { No } \\
N=20\end{array}$ & & \\
\hline Primary & $26(7.9)$ & $1(5.3)$ & $1.54(0.20-12.00)$ & 1.000 \\
\hline JHS & $93(28.2)$ & $5(26.3)$ & $1.11(0.38-3.14)$ & 1.000 \\
\hline SHS & $45(13.6)$ & $3(15.8)$ & $0.84(0.24-3.01)$ & 0.734 \\
\hline Vocational & $6(1.8)$ & $0(0.0)$ & - & 1.000 \\
\hline Tertiary & 134 (40.6) & $9(47.4)$ & $0.76(0.30-1.92)$ & 0.634 \\
\hline \multicolumn{5}{|l|}{ Couple involvement } \\
\hline Yes & $7(1.9)$ & $0(0.0)$ & - & 1.000 \\
\hline No & $364(98.1)$ & $20(100.0)$ & - & 1.000 \\
\hline \multicolumn{5}{|l|}{ Status } \\
\hline First ever & $232(62.5)$ & $12(60.0)$ & $1.11(0.44-2.79)$ & 0.817 \\
\hline Continuing & $139(37.5)$ & $8(40.0)$ & $0.90(0.36-2.25)$ & 0.817 \\
\hline
\end{tabular}


Table 3: Sociodemographic determinants of continuation of Implanon/Nexplanon use at one year postpartum among women at the Korle-Bu Teaching Hospital 2012 -2015, Accra, Ghana.

\begin{tabular}{|c|c|c|c|c|}
\hline \multirow{2}{*}{ Variable } & \multicolumn{2}{|c|}{ Postpartum Uptake } & \multirow{2}{*}{ OR (95\% C.I) } & \multirow{2}{*}{ P-value } \\
\hline & Yes, $N=363$ & No, $N=28$ & & \\
\hline \multicolumn{5}{|l|}{ Age group } \\
\hline$<20$ & $22(6.1)$ & $1(3.6)$ & $1.74(0.23-13.42)$ & 1.000 \\
\hline $20-29$ & $177(48.8)$ & $12(42.9)$ & $1.27(0.58-2.76)$ & 0.563 \\
\hline $30-39$ & $158(43.5)$ & $15(53.6)$ & $0.67(0.31-1.44)$ & 0.328 \\
\hline 40 and above & $6(1.7)$ & $0(0.0)$ & - & 1.000 \\
\hline \multicolumn{5}{|l|}{ Parity } \\
\hline $\mathrm{P} 1$ & $122(33.6)$ & $14(50.0)$ & $0.51(0.23-1.10)$ & 0.099 \\
\hline P2-P4 & $221(60.9)$ & $14(50.0)$ & $1.56(0.72-3.36)$ & 0.317 \\
\hline P5 and above & $20(5.5)$ & $0(0.0)$ & - & 0.382 \\
\hline Abortions & $\mathrm{N}=86$ & $\mathbf{N}=8$ & & \\
\hline 1 & $47(54.7)$ & $5(62.5)$ & $0.72(0.16-3.22)$ & 0.728 \\
\hline 2 & $28(32.6)$ & $2(25.0)$ & $1.45(0.27-7.64)$ & 1.000 \\
\hline $3+$ & $11(12.8)$ & $1(12.5)$ & $1.03(0.12-9.16)$ & 1.000 \\
\hline Occupation & $\mathrm{N}=325$ & $N=26$ & & \\
\hline Professional & $107(32.9)$ & $12(46.2)$ & $0.57(0.26-1.28)$ & 0.198 \\
\hline Skilled & $61(18.8)$ & $3(11.5)$ & $1.77(0.52-6.09)$ & 0.440 \\
\hline Semi-skilled & $11(3.4)$ & $1(3.8)$ & $0.88(0.11-7.06)$ & 0.609 \\
\hline Trader & $99(30.5)$ & $5(19.2)$ & $1.84(0.67-5.02)$ & 0.271 \\
\hline Housewife & $7(2.2)$ & $1(3.8)$ & $0.55(0.07-4.65)$ & 0.463 \\
\hline Student & $21(6.5)$ & $2(7.7)$ & $0.83(0.18-3.75)$ & 0.684 \\
\hline Unemployed & $19(5.8)$ & $2(7.7)$ & $0.75(0.16-3.39)$ & 0.662 \\
\hline Educational level & $\mathrm{N}=324$ & $\mathrm{~N}=25$ & & \\
\hline No formal education & $27(8.3)$ & $0(0.0)$ & - & 0.240 \\
\hline Primary & $26(8.0)$ & $1(4.0)$ & $2.09(0.27-16.11)$ & 0.707 \\
\hline JHS & $95(29.3)$ & $3(12.0)$ & $3.03(0.89-10.36)$ & 0.068 \\
\hline SHS & $43(13.3)$ & $5(20.0)$ & $0.61(0.22-1.71)$ & 0.363 \\
\hline Vocational & $6(1.9)$ & $0(0.0)$ & - & 1.000 \\
\hline Tertiary & $127(39.2)$ & $16(64.0)$ & $0.36(0.16-0.85)$ & 0.020 \\
\hline \multirow{2}{*}{ Variable } & Postpartum & & \multirow{2}{*}{ OR $(95 \%$ CI $)$} & \multirow{2}{*}{ P-value } \\
\hline & Yes, $N=363$ & No, $N=28$ & & \\
\hline Yes & $6(1.7)$ & $1(3.6)$ & $0.45(0.05-3.91)$ & 0.408 \\
\hline No & $357(98.3)$ & $27(96.4)$ & $2.20(0.26-18.97)$ & 0.408 \\
\hline \multicolumn{5}{|l|}{ Status } \\
\hline First ever & $225(62.0)$ & $19(67.9)$ & $0.77(0.34-1.76)$ & 0.686 \\
\hline Continuing & $138(38.0)$ & $9(32.1)$ & $1.29(0.57-2.94)$ & 0.686 \\
\hline
\end{tabular}

Across the study period the commonest reason for discontinuation of postpartum Implanon/Nexplanon use was desire for another pregnancy with $55 \%, 42.9 \%$ and $71.1 \%$ of women discontinuing at 6 months, 1 year and 2 years respectively (Table 5, 6 and 7 respectively).

Side effects/ health concerns was the other common reason for discontinuation, and this had a simple downward trend over the study period with $35 \%, 28.6 \%$ and $18.9 \%$ of women discontinuing use at 6 months, 1 year and 2 years respectively (Table 5, 6 and 7 respectively).

\section{DISCUSSION}

Within 6 months of uptake of postpartum Implanon/Nexplanon, close to $95 \%$ of users still continued its use which decreased to about $86.5 \%$ at 2 years postpartum. These figures are in tandem with work done by Woo et al in the United States. ${ }^{10}$ Even though experiences from our unit show that women who seek contraceptive methods at the facility often utilize the same facility for their post-uptake care and removal, it is possible that some of the women may have removed their implants at some other health facilities without informing the unit. 
Table 4: Sociodemographic determinants of continuation of Implanon/Nexplanon use at two years postpartum among women at the Korle-Bu Teaching Hospital 2012 -2015, Accra, Ghana.

\begin{tabular}{|c|c|c|c|c|}
\hline \multirow[b]{2}{*}{ Variable } & \multicolumn{2}{|c|}{ Postpartum Uptake } & \multirow[b]{2}{*}{ OR $(95 \%$ C.I $)$} & \multirow[b]{2}{*}{ P-value } \\
\hline & $\begin{array}{l}\text { Yes } \\
\mathrm{N}=338\end{array}$ & $\begin{array}{l}\text { No } \\
\mathrm{N}=53\end{array}$ & & \\
\hline \multicolumn{5}{|l|}{ Age group } \\
\hline$<20$ & $22(6.5)$ & $1(1.9)$ & $3.62(0.48-27.44)$ & 0.341 \\
\hline $20-29$ & $155(45.9)$ & $34(64.2)$ & $0.47(0.26-0.86)$ & 0.017 \\
\hline $30-39$ & $155(45.9)$ & $18(34.0)$ & $1.65(0.90-3.02)$ & 0.136 \\
\hline 40 and above & $6(1.8)$ & $0(0.0)$ & - & 1.000 \\
\hline \multicolumn{5}{|l|}{ Parity } \\
\hline P1139 & $113(33.4)$ & $23(43.4)$ & $0.66(0.36-1.18)$ & 0.165 \\
\hline P2-P4 & $206(60.9)$ & $29(54.7)$ & $1.29(0.72-2.31)$ & 0.451 \\
\hline P5 and above & $19(5.6)$ & $1(1.9)$ & $3.10(0.41-23.63)$ & 0.497 \\
\hline Abortions & $\mathbf{N}=\mathbf{8 1}$ & $\mathrm{N}=13$ & & \\
\hline 1 & $44(54.3)$ & $8(61.5)$ & $0.74(0.22-2.47)$ & 0.767 \\
\hline 2 & $26(32.1)$ & $4(30.8)$ & $1.06(0.30-3.78)$ & 1.000 \\
\hline $3+$ & $11(13.6)$ & $1(7.7)$ & $1.89(0.22-15.98)$ & 1.000 \\
\hline Occupation & $\mathrm{N}=304$ & $\mathrm{~N}=47$ & & \\
\hline Professional & $103(33.9)$ & $16(34.0)$ & $0.99(0.52-1.90)$ & 1.000 \\
\hline Skilled & $51(16.8)$ & $13(27.7)$ & $0.53(0.26-1.07)$ & 0.102 \\
\hline Semi-skilled & $11(3.6)$ & $1(2.1)$ & $1.73(0.22-13.69)$ & 1.000 \\
\hline Trader & $94(30.9)$ & $10(21.3)$ & $1.66(0.79-3.47)$ & 0.229 \\
\hline Housewife & $6(2.0)$ & $2(4.3)$ & $0.45(0.09-2.31)$ & 0.291 \\
\hline Student & $21(6.9)$ & $2(4.3)$ & $1.67(0.38-7.37)$ & 0.752 \\
\hline Unemployed & $18(5.9)$ & $3(6.4)$ & $0.92(0.26-3.26)$ & 0.751 \\
\hline Educational level & $N=364$ & $\mathrm{~N}=48$ & & \\
\hline No formal education & $24(8.0)$ & $3(6.3)$ & $1.06(0.31-3.66)$ & 1.000 \\
\hline Primary & $24(8.0)$ & $3(6.3)$ & $1.06(0.31-3.66)$ & 1.000 \\
\hline JHS & $90(29.9)$ & $8(16.7)$ & $1.64(0.74-3.64)$ & 0.280 \\
\hline SHS & $37(12.3)$ & $11(22.9)$ & $0.38(0.18-0.81)$ & 0.016 \\
\hline Vocational & $5(1.7)$ & $1(2.1)$ & $0.65(0.07-5.72)$ & 0.527 \\
\hline Tertiary & $121(40.2)$ & $22(45.8)$ & $0.59(0.32-1.08)$ & 0.106 \\
\hline \multicolumn{5}{|l|}{ Couple involvement } \\
\hline Yes & $6(1.8)$ & $1(1.9)$ & $0.94(0.11-7.96)$ & 1.000 \\
\hline No & $332(98.2)$ & $52(98.1)$ & $1.06(0.13-9.02)$ & 1.000 \\
\hline \multicolumn{5}{|l|}{ Status } \\
\hline First ever & $209(61.8)$ & $35(66.0)$ & $0.83(0.45-1.53)$ & 0.647 \\
\hline Continuing & $129(38.2)$ & $18(34.0)$ & $1.20(0.65-2.21)$ & 0.647 \\
\hline
\end{tabular}

Table 5: Reasons for removal of Implanon/Nexplanon at six months postpartum among women at the KorleBu Teaching Hospital 2012 -2015, Accra, Ghana.

\begin{tabular}{|lll|}
\hline Reasons for removal & Frequency & Percent \\
\hline Wanted to become pregnant & 11 & 55 \\
\hline Husband disapproved & 1 & 5 \\
\hline Infrequent sex/husband away & 1 & 5 \\
\hline Side effects/health concerns & 7 & 35 \\
\hline Total & 20 & 100 \\
\hline
\end{tabular}

These continuation rates were however higher than those recorded in the Netherlands. ${ }^{11}$ The continuation rates in this study are high when compared to the $18-63 \%$ contraceptive discontinuation rates recorded in most developing countries. ${ }^{6}$ This may be due to effective counselling for contraceptive uptake which is an integral part of the service offered at the Reproductive Health and Family Planning Unit of the Korle-Bu teaching Hospital.

This study found no significant effect of timing of the uptake of postpartum Implanon/Nexplanon (immediate, delayed or interval) on the continuation rates. These findings are similar to that of Luu et al in Rhode Islands. ${ }^{12}$ Given that immediate postpartum Implanon provision has been shown to be cost effective in preventing unwanted pregnancies, the findings in this 
study suggest that more women should be encouraged to opt for this whiles they are still in the health facilities where they delivered. ${ }^{13}$

Table 6: Reasons for removal of Implanon/Nexplanon at one year postpartum among women at the Korle-

Bu Teaching Hospital 2012 -2015, Accra, Ghana.

\begin{tabular}{|lll|}
\hline Reasons for removal & Frequency & Percent \\
\hline Wanted to become pregnant & 12 & 42.9 \\
\hline Husband disapproved & 1 & 3.6 \\
\hline Infrequent sex/husband away & 3 & 10.7 \\
\hline Religious reasons & 1 & 3.6 \\
\hline Separated from husband & 2 & 7.1 \\
\hline Side effects/health concerns & 8 & 28.6 \\
\hline No specific reason & 1 & 3.6 \\
\hline Total & 28 & 100.0 \\
\hline
\end{tabular}

Table 7: Reasons for removal of Implanon/Nexplanon at two years postpartum among women at the Korle-

Bu Teaching Hospital 2012 -2015, Accra, Ghana.

\begin{tabular}{|lll|}
\hline Reasons for removal & Frequency & Percent \\
\hline Wanted to become pregnant & 38 & 71.7 \\
\hline Infrequent sex/husband away & 2 & 3.8 \\
\hline Separated from husband & 2 & 3.8 \\
\hline Side effects/health concerns & 10 & 18.9 \\
\hline No specific reason & 1 & 1.9 \\
\hline Total & 53 & 100.0 \\
\hline
\end{tabular}

\begin{tabular}{|c|c|c|c|c|}
\hline \multirow{7}{*}{ 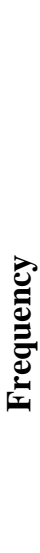 } & 380 & $\begin{array}{c}371 \\
(94.9 \%)\end{array}$ & $\begin{array}{c}363 \\
(92.8 \%)\end{array}$ & \multirow{5}{*}{$\begin{array}{c}338 \\
(86.4 \%)\end{array}$} \\
\hline & 360 & & & \\
\hline & 350 & & & \\
\hline & 340 & & & \\
\hline & 330 & & & \\
\hline & & 6months & Within a year & Within 2 years \\
\hline & & & uration & \\
\hline
\end{tabular}

Figure 1: Continuation rates for Implanon/Nexplanon among women at 6 months, 1 year and 2 years postpartum at the Korle-Bu Teaching Hospital 2012 2015, Accra, Ghana.

In this study, age of clients, parity, history of abortions, occupation, educational level, involvement of their partners and whether they were first ever users or continuing did not affect continuation rates of Implanon/Nexplanon use 6 months postpartum. This finding is at variance with the finding of Woo et al at John Hopkins where women who were continuing users of postpartum Implanon were more likely to continue the use at 6 months post- partum. ${ }^{10}$ Women whose educational level was up to the tertiary level were significantly less likely to continue Implanon/Nexplanon use a year postpartum. The reason for this observation is not clear and further studies are needed to be able to explain it. These women however are likely to have a higher age selection due to time spent in school and the need to complete their families on time.

The age group between 20 and 29 were also significantly less likely to continue Implanon/Nexplanon use at 1 year and two years post- partum. This finding is worrying since this age group constitutes women who are in likely to be in the peak of their reproductive life in Ghana. There is the need to perform qualitative studies in this area to shed more light on the reason for this finding. Women who had had a maximum of senior high school education were significantly less likely to continue Implanon/Nexplanon use at 2 years post- partum.

Teenagers were more likely to continue postpartum Implanon/Nexplanon use even though this was not a significant finding. A study in Ethiopia however found the teenage age group to be more likely to discontinue Implanon use. ${ }^{14}$ This is a window of opportunity to be explored to provide effective long acting reversible contraception for this age group to prevent unwanted pregnancies. It may be a way to prevent rapid repeat pregnancies in adolescents as has been observed by Toccee et al in Colorado and Lewis et al in Perth, Australia. ${ }^{15,16}$

Close to half of the study population wanted to become pregnant within 6 months postpartum and therefore had the postpartum Implanon/Nexplanon removed. This is unusual and it may be because these women gave answers that they thought were socially desirable instead of giving the exact reason for their opting for removal. Two fifth of respondents who had their postpartum Implanon/Nexplanon removed at 1 year did so because they wanted to become pregnant. At two-year postpartum, the high percentage of Implanon/Nexplanon removals to allow for the next pregnancy. This finding is different from that found in Jos in which the main reason for removal of Implanon was because of menstrual abnormalities. ${ }^{17}$ The study in Jos however focused on reasons for removal of Etonorgestrel Implants in general and not specific to postpartum ones. Interestingly, at 6 months, 1 year and 2 years post- partum, the second main reason for the discontinuation of postpartum Implanon/Nexplanon use was because of side effects. This agrees with works done by other authors in which one of the main reasons for discontinuation of Implanon use was because of side effects. ${ }^{18,19}$

\section{CONCLUSION}

Post-partum Implanon/Nexplanon continuation rates are high and remain as a viable choice for reduction of unplanned pregnancies post- delivery. There still needs to 
be improved public health education on the various side effects to maintain or even enhance the current continuation rates.

\section{ACKNOWLEDGMENTS}

We are grateful to the staff of the Reproductive Health and Family Planning Unit of the Korle-Bu Teaching Hospital for assisting us with the data collection. Our gratitude to Maxfield Okere who assisted with cleaning up of the data and the analysis.

Funding: No funding sources

Conflict of interest: None declared

Ethical approval: The study was approved by the Institutional Ethics Committee

\section{REFERENCES}

1. Ghana Statistical Service (GSS), Ghana Health Service (GHS), and ICF Macro International. Ghana Demographic and Health Survey, 2014. Available at: http://microdata.worldbank.org/index.php/catalog/2373.

2. Stover J, Ross J. How increased contraceptive use has reduced maternal mortality. Matern child health $\mathrm{J}$. 2010;14(5):687-95.

3. Ahmed S, Ahmed S, McKaig C, Begum N, Mungia J, Norton $\mathrm{M}$, et al. The effect of integrating family planning with a maternal and newborn health program on postpartum contraceptive use and optimal birth spacing in rural Bangladesh. Studies in Family Planning. 2015;46(3):297-312.

4. Gurtcheff SE, Turok DK, Stoddard G, Murphy PA, Gibson M, Jones KP. Lactogenesis after early postpartum use of the contraceptive implant: a randomized controlled trial. Obstet Gynecol. 2011;117(5):1114-21.

5. Han L, Teal SB, Sheeder J, Tocce K. Preventing repeat pregnancy in adolescents: is immediate postpartum insertion of the contraceptive implant cost effective? Am J Obstet Gynecol. 2014;211(1):24-e1.

6. Bradley SE, Schwandt H, Khan S. Levels, trends, and reasons for contraceptive discontinuation. DHS Analyt Stud. 2009;20.

7. Azmat SK, Hameed W, Mustafa G, Hussain W, Ahmed A, Bilgrami M. IUD discontinuation rates, switching behavior, and user satisfaction: findings from a retrospective analysis of a mobile outreach service program in Pakistan. International $\mathrm{J}$ women's health. 2013;5:19.

8. Ali MM, Cleland JG, Shah IH, World Health Organization. Causes and consequences of contraceptive discontinuation: evidence from 60 demographic and health surveys. Available https://www.who.int/reproductivehealth/publications/famil y_planning/9789241504058/en/
9. Haddad LB, Nour NM. Unsafe abortion: unnecessary maternal mortality. Reviews in Obstet Gynecol. 2009;2(2):122.

10. Woo I, Seifert S, Hendricks D, Jamshidi RM, Burke AE, Fox MC. Six-month and 1-year continuation rates following postpartum insertion of implants and intrauterine devices. Contracept. 2015;92(6):532-5.

11. Teunissen AM, Grimm B, Roumen FJ. Continuation rates of the subdermal contraceptive Implanon ${ }^{\circledR}$ and associated influencing factors. Euro J Contracept Reprod Heal Care. 2014;19(1):15-21.

12. Ireland LD, Goyal V, Raker CA, Murray A, Allen RH. The effect of immediate postpartum compared to delayed postpartum and interval etonogestrel contraceptive implant insertion on removal rates for bleeding. Contracept. 2014;90(3):253-8.

13. Gariepy AM, Duffy JY. Cost-effectiveness of immediate compared with delayed postpartum etonogestrel implant insertion. Obstet Gynecol. 2015;126(1):47.

14. Tadesse A, Kondale M, Agedew E, Gebremeskel F, Boti $\mathrm{N}$, Oumer B. Determinant of Implanon discontinuation among women who ever used Implanon in Diguna Fango District, Wolayita zone, southern Ethiopia: a communitybased case control study. International J Reprod Med. 2017.

15. Tocce KM, Sheeder JL, Teal SB. Rapid repeat pregnancy in adolescents: do immediate postpartum contraceptive implants make a difference? Am J Obstet Gynecol. 2012;206(6):481-e1.

16. Lewis LN, Doherty DA, Hickey M, Skinner SR. Implanon as a contraceptive choice for teenage mothers: a comparison of contraceptive choices, acceptability and repeat pregnancy. Contracept. 2010;81(5):421-6.

17. Muthir JT, Nyango DD. Indications for removal of etonogestrel implant within two years of use in Jos, Nigeria. East African Med J. 2010;87(11).

18. Mrwebi KP, Ter Goon D, Owolabi EO, Adeniyi OV, Seekoe E, Ajayi AI. Reasons for discontinuation of Implanon among users in Buffalo City Metropolitan Municipality, South Africa: A cross-sectional study. African J Reproduct Heal. 2018;22(1):113-9.

19. Melkamu Asaye M, Syoum Nigussie T, Mequannt Ambaw W. Early Implanon discontinuation and associated factors among Implanon user women in Debre Tabor town, public health facilities, Northwest Ethiopia, 2016. International J Reproduct Med. 2018.

Cite this article as: Mumuni K, Asah-Opoku K, Ganu V, Samba A. Postpartum Implanon/Nexplanon continuation rates and associated factors among women who ever used Implanon/Nexplanon in a tertiary hospital in Accra, Ghana. Int J Reprod Contracept Obstet Gynecol. 2019;8:3304-10. 